\title{
Simulated water productivity in Gansu Province, China
}

\author{
Jinyan Zhan ${ }^{\mathrm{a}, *}$, Zhongxiao Sun ${ }^{\mathrm{a}}$, Zhan Wang ${ }^{\mathrm{b}}$, Jiancheng Chen ${ }^{\mathrm{c}}$, Zhaohua $\mathbf{L i}^{\mathrm{d}}$ \\ a State Key Laboratory of Water Environment Simulation, School of Environment, Beijing Normal University, Beijing 100875, China \\ ${ }^{\mathrm{b}}$ Center for Chinese Agricultural Policy, Institute of Geographic Sciences and Natural Resources Research, Chinese Academy of Sciences, Beijing 100101, China \\ 'School of Economics E' Management, Beijing Forestry University, No. 35, Tsinghua East Road, Haidian District, Beijing 100083, China \\ ${ }^{\mathrm{d}}$ Faculty of Resources and Environmental Science, Hubei University, Wuhan, Hubei 430062, China
}

\section{A R T I C L E I N F O}

\section{Article history:}

Received 5 October 2014

Received in revised form 21 January 2015

Accepted 2 February 2015

Available online 24 February 2015

\section{Keywords:}

Water productivity

Gansu Province

Computable General Equilibrium model

Sustainable development

\begin{abstract}
A B S T R A C T
Economic value of water and economic analysis of water use management in Gansu Province of China have attracted widespread public attention. With the socioeconomic development, research on water resources has become more important than before. In this study, we define "water productivity" as the changes of economic production outputs of sectoral activities in every cubic meter of water input, which is also the technical coefficient of water resource use in each sector. According to Computable General Equilibrium (CGE) framework, based on the Input-Output Table 2007 and water resources bulletin of Gansu Province, we introduced the water into the ORANI-G (A Generic Single-Country Computable General Equilibrium model) model through the nested constant elasticity of substitution (CES) production function to analyze the changes of economic productions caused by water supply changes. We then examined water productivity in different sectors. Empirical results showed that current water productivity is underestimated. Agricultural water productivity is lower than that of the secondary and tertiary industries, even although agricultural water use is the largest part of water use in Gansu Province, and therefore improving agricultural water productivity can greatly mitigate the water shortage. Simulation results indicate that industrial transformation and development of water-saving industries will also mitigate water scarcity. Moreover, sensitivity analysis shows that the empirical results are robust under different scenarios. The results also show that higher constant elasticity of substitution rate (CES) between water and other production factors will contribute to sustainable development.
\end{abstract}

(c) 2015 Published by Elsevier Ltd.

\section{Introduction}

Water is one of the most important elements for human living on the earth, and the water resource shortage has received wide attention for a long time. The global water scarcity was driven by the population growth, there was only about $2 \%$ population suffering from water scarcity at the early 1900s in the world, but this number increased to $9 \%$ in the 1960s and 35\% by 2005 (Kummu et al., 2010). Climate change will also affect water balance (Wu et al., 2014). Agricultural water use currently takes up the largest proportion of total water consumption in the world as well as China. According to United Nations Food \& Agriculture Organization report, the agriculture has consumed over $70 \%$ of the total water resource in the world (Brown and Matlock, 2011). However, the water use efficiency of agricultural irrigation is still

\footnotetext{
* Corresponding author. Tel.: +86 106488 8990; fax: +86 1064856533.

E-mail addresses: zhanjy@bnu.edu.cn, zhanjinyan.bnu@gmail.com (J. Zhan), sunzhongxiaocug@gmail.com (Z. Sun), lizwang128@gmail.com (Z. Wang), chenjc1963@163.com (J. Chen), zli@hubu.edu.cn (Z. Li).
}

quite low, and, the water use efficiency of grain production is even lower than $60 \%$ (Calzadilla et al., 2011c). The increasingly serious water resource shortage makes it very necessary to study how to use water more efficiently to mitigate the impacts of water scarcity on agricultural production.

China is one of the 13 countries with the scarcest water resources, with the water resource per capital of about $2185 \mathrm{~m}^{3}$, which is less than one third of world average level (MartinCarrasco et al., 2013). The serious water resource shortage has become a key limiting factor of the sustainable socioeconomic development, and integrated water resources management for sustainable water utilization to efficiently deal with water scarcity has become an important research issue in China (Liu et al., 2008). In particular, Gansu Province is located in the arid and semi-arid regions in Northwest China, where there is serious water shortage and the agricultural water use accounts for a large proportion of water consumption. Zhang et al. found water scarcity and stress was more severe over time and distinct on spatial variation in Zhangye City, Gansu Province (Zhang et al., 2014). However, the agricultural water price is lower than the cost and flooding 
irrigation is widely used in most part of Gansu Province (Shi et al., 2010), which lead to the low water use efficiency. There is a high potential to improve the water use efficiency by carrying out water use reformation and implementing efficient water resources management in this region.

The economic value of the water resource receives more and more attention as the socioeconomic development accelerates, and water resources management has expanded to the socioeconomic research scope (Deng et al., 2014). It is necessary to take into account the influence of socioeconomic factors when trying to mitigate the water scarcity in an integrated water resources management planning. Besides, it is vitally important to analyze the relationships between economic production and water use in order to improve the water use structure and promote the water use efficiency, which is also a key issue in the integrated water resource management in China. There have been a lot of case studies on the water resources management and water use efficiency in the socioeconomic system worldwide, the methods in which can be summarized into four categories as follows: (1) multi-objective programming for the optimal allocation of water resources (Yapo et al., 1998; Farmani et al., 2005; Xevi and Khan, 2005; Cheong et al., 2010); (2) quadratic programming for the optimal allocation of water resources (Goulter, 1995; Huang, 1996; Huang and Loucks, 2000; Huang et al., 2007; Liu et al., 2012a,b); (3) system dynamics analysis of water resources management (Stave, 2003; Winz et al., 2009; Qi and Chang, 2011; Sušnik et al., 2012; Chen and Wei, 2014); and (4) analysis of economic value of water use with the CGE (Computable General Equilibrium) model. There are four main categories of models about water resources management and efficiency currently. First, the multi-objective programming and quadratic programming generally focus on the allocation of water quantity rather than the value of water resources. Second, the Input-Output model based on the multiobjective programming can calculate the shadow price, but it assumes the production function is linear and the relationship between the input and output is fixed, without taking reaction to the price mechanism into consideration. However, the production function is generally non-linear in the practical economic system, and the price mechanism plays a fundamental role in influencing the input and output. Third, the system dynamics simplifies the complex issues from the perspective of the system, but it puts more emphasis on the feedback mechanism and has very strict requirements on the parameterization for the long-term simulation. By comparison, the CGE model is a system model that simplifies the entire economic system and takes into account the interaction between different components of the economic system. Moreover, it is based on the theory of supply and demand, which regulates the supply and demand of water resources with the price mechanism. We consequently chose CGE model to analyze the role of the water resources in the entire economic system.

The CGE model is widely used to analyze the socioeconomic policy and assess the efficiency of water allocation among different sectors (Chen et al., 2005; Baker, 2011; Wittwer, 2012). Most researches with the CGE model focused on the water rights exchanges (Seung et al., 1997; Gómez et al., 2004; Diao et al., 2005) and integrated management of surface water and ground water (Diao et al., 2008; Calzadilla et al., 2011a). Currently, the most popular and robust CGE model include the TERM-H2O (The Enormous Regional Model-H2O) model and GTAP-W (Global Trade Analysis Project-Water) model. The TERM-H2O model is a multi-regional model, which is developed by Mark Horridge from Australian Center for Policy Research. Wittwer in (2006) firstly used the TERM-H2O model to analyze the role of urban and rural water trade in meeting the water demand of the future economic development. Thereafter, Schreider (2009) introduced random precipitation into the TERM-H2O model to predict the one-weekly and two-weekly water price. The GTAP-W model is developed by Burniauxand and Truong based on the GTAP-E model, and is generally used to analyze the impacts of sustainable water use in the agricultural sector on the whole economic system (Berrittella et al., 2007). Alvaro et al. have carried out a series of studies on the agricultural production with the GTAP-W model (Calzadilla et al., 2010, 2011a,b,c, 2014).

The economic value of water use can be more accurately analyzed with the CGE model that involves the water resource. This study improved the ORANI-G model by involving the water resource used as a production factor, and the water resource and other production factors were involved into the constant elasticity of substitution (CES) production function. A dataset for the improved ORANI-G model was established on the basis of the Input-Output Table 2007 and water resource bulletin of Gansu Province; thereafter, the impacts of water resource change on the socioeconomic development and water productivity were analyzed with scenario analysis, and sensitivity analysis was carried out. In this study, the water productivity was defined as the changes of economic production outputs of sectoral activity in every cubic meter of water input, which is also the technical coefficient of water resource to interpret the relationships between economic production and water use in each sector (Playán and Mateos, 2006; Miller and Blair, 2009). In the rest of paper, Section 2 introduces the study area. Thereafter, the data description and methodology are given in Section 3, which explains the structure of the ORANI-G model in detail, and several key functions in the modified part are listed. In Section 4, empirical results and their sensitivity analysis are discussed under scenarios. Finally, the conclusion and discussion are given in Sections 5 and 6.

\section{Study area}

Gansu Province is located at $32^{\circ} 31^{\prime} \sim 42^{\circ} 57^{\prime} \mathrm{N}, 92^{\circ} 13^{\prime}$ $\sim 108^{\circ} 46^{\prime} \mathrm{E}$, which is at the upstream of Yellow River and the intersection area of the Loess plateau, the Qinghai-Tibet plateau, and the Inner Mongolia plateau. Gansu Province expands across over $1600 \mathrm{~km}$ and covers 0.454 million $\mathrm{km}^{2}$, accounting for about $4.72 \%$ of total land area of China (Fig. 1).

\subsection{Economy of Gansu Province ${ }^{1}$}

The total population in Gansu Province was 25.78 million in 2012, including 9.99 million urban population, with an urbanization rate of $38.8 \%$, which is lower than $40 \%$, indicating Gansu Province is still a developing region with a large proportion of rural population. The total GDP of Gansu Province was about 89.7 billion US dollar (USD) in 2012, including 12.3 billion USD from the agriculture industry, 41.3 billion USD from the secondary industry, and 36.1 billion USD from the Tertiary Industry (Fig. 2). The ratio of three industries is about $7: 23: 20$, the proportion of the agriculture industry is relatively higher than that of other provinces in China, and the agriculture industry accounts for over $20 \%$ of the total GDP in most part of Gansu Province. For example, the proportion of the agriculture industry in the total GDP in Zhangye City and Dingxi City reached $28 \%$ and $30 \%$, respectively.

\subsection{Water use in Gansu Province ${ }^{2}$}

Gansu Province expands across three large basins including the Yellow River Basin, Yangtze River Basin and inland river basin, involving nine river systems including Zhaohe River, Huangshui

\footnotetext{
1 Gansu Province Development Yearbook 2013.

2 Gansu Water Resource bullet in 2007.
} 


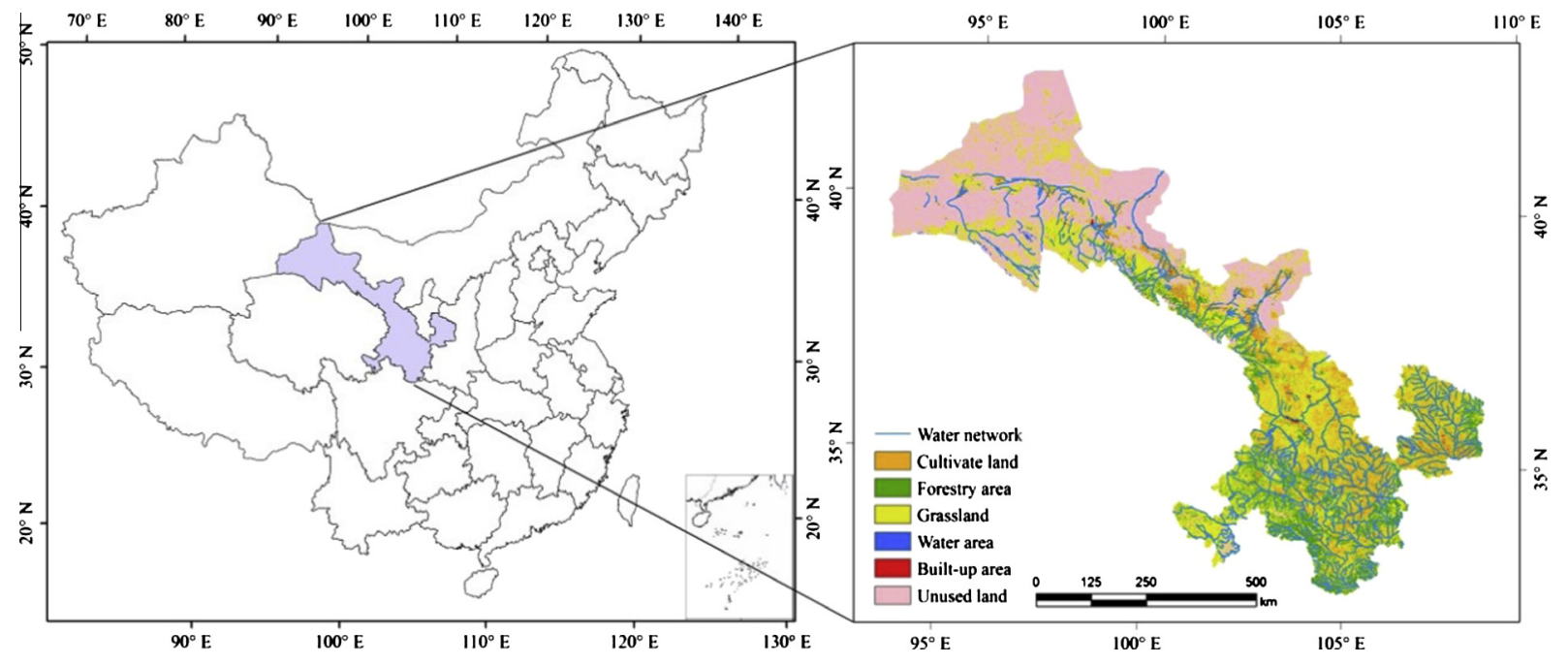

Fig. 1. Location, water network and land use of the study area in Gansu Province, China.

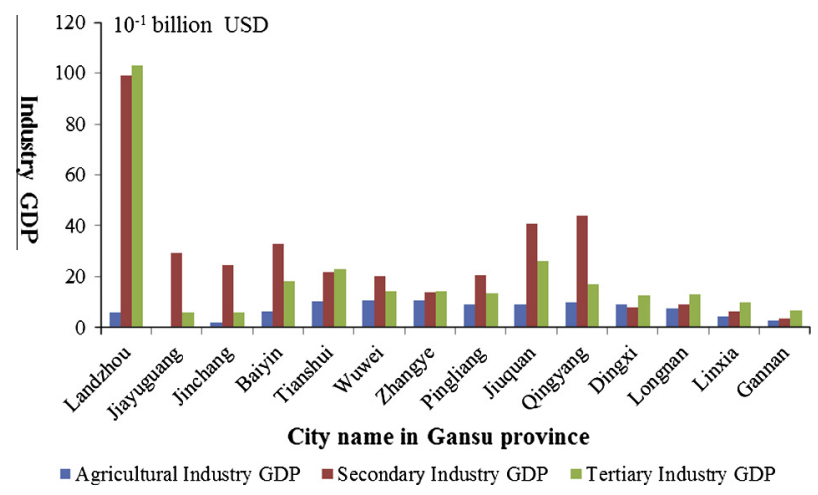

Fig. 2. Economic production in prefectures of Gansu (100 million USD).

River, and 6 main streams of Yellow River: Weihe River, Jinghe River, Jialing River, Shiyang River, Heihe River, and Shule River. The total water consumption of Guansu Province was 12.3 billion $\mathrm{m}^{3}$ in 2007, including 7.7 billion $\mathrm{m}^{3}$ from inland rivers, 4.3 billion $\mathrm{m}^{3}$ from Yellow River, and 0.3 billion $\mathrm{m}^{3}$ from Yangtze River. Besides, the water consumption of irrigated cultivation, other agriculture, industrial, urban construction, residential, and ecological water use in 2007 reached 9.3, 0.5, 1.3, 0.2, 0.6, and 0.2 billion $\mathrm{m}^{3}$, respectively (Table 1 ).

\section{Data and methodology}

\subsection{Data and parameterization}

In this paper, we used the Input-Output Table 2007 of Gansu Province which we got it from the Statistics Bureau of Gansu Province with 33 sectors aggregated from 144 sectors. According to the empirical data of China water price website (http://price. h2o-china.com/gansusheng_2364) and the investigation data, the agricultural water price was $0.013 \mathrm{USD} / \mathrm{m}^{3}$, the industrial water price was $0.33 \mathrm{USD} / \mathrm{m}^{3}$, and water price of the tertiary industry was $0.4 \mathrm{USD} / \mathrm{m}^{3}$ on average. The total economic value of water use is calculated by multiplying the average water price by the amount of water use for each sector.

The parameter values in the ORANI-G model were empirically determined according to the parameterization scheme for China in the ORANI-G model. When the average per capita income increases from 100 to 3000 USD (price in 1970), Frisch Index will increase from -7.5 to -2.0 (Liu et al., 2012a,b). The average per capita income in Gansu was about 1380 USD in 2007 (current price in 2007), the Frisch Index was therefore set to be -3.82 . Besides, this study determined the value of constant elasticity of substitution of water to all other production factors according to the results of previous research (Liu, 2013) and the local conditions of the study area, Liu determined the value of this parameter based on their empirical studies and the parameters of the China Version of ORANI-G model with 122 sectors, which was developed by Center of Policy Studies, Australia. In this study, the parameter was determined according to the research of Liu and the local conditions of the study area, which was finally set to be 0.05 (Liu, 2013).

\subsection{Methodology}

According to comparison with the conventional CGE model, we introduced water into the CES production function. Based on the water extended-Input-Output table, we rebuilt the database for the ORANI-G model, and discussed the water productivity which represents the changes of economic production outputs of sectoral activities in every cubic meter of water input. Fig. 3 describes the technical roadmap of this study. To analyze the water productivity in different sectors, we designed scenarios to explore the contribution of water resource use to economic production. Considering the stability of CES in theory, we also tested the sensitivity of the elasticity between water and other primary factors to water productivity in our model in the following sections.

\subsubsection{Model improvement}

ORANI-G is a single county CGE model, which is widely used for economic policy analysis and academic research in Australia and other counties (http://www.copsmodels.com/oranig.htm). Similar as other CGE models, it includes the production market, government market, household market, and trade market based on the market clearing equilibrium. Based on the original ORANI-G model, we introduced water into the nested CES production function (Fig. 4), in which water is the same as other production factors in the CES production function.

Modified production equation referred to water in the system as follows, while other functions and equations in the production structure were omitted. Eqs. (1)-(7) show the relationship among water and other production factors in the nested CES production 
Table 1

Water use in Gansu Province in $2007\left(10^{8} \mathrm{~m}^{3}\right)$.

\begin{tabular}{|c|c|c|c|c|c|c|c|}
\hline Watershed & Cultivated irrigation & Other agriculture & Industrial & Urban construction & Residential & Ecological environment & Total \\
\hline Inland Rivers & 64.71 & 4.31 & 3.40 & 0.42 & 1.96 & 1.78 & 76.57 \\
\hline Yellow River & 26.34 & 1.01 & 9.77 & 1.35 & 3.78 & 1.13 & 43.38 \\
\hline Yangzi River & 2.07 & 0.09 & 0.15 & 0.13 & 0.68 & 0.03 & 3.15 \\
\hline Total & 93.12 & 5.41 & 13.31 & 1.90 & 6.42 & 2.94 & 123.10 \\
\hline
\end{tabular}

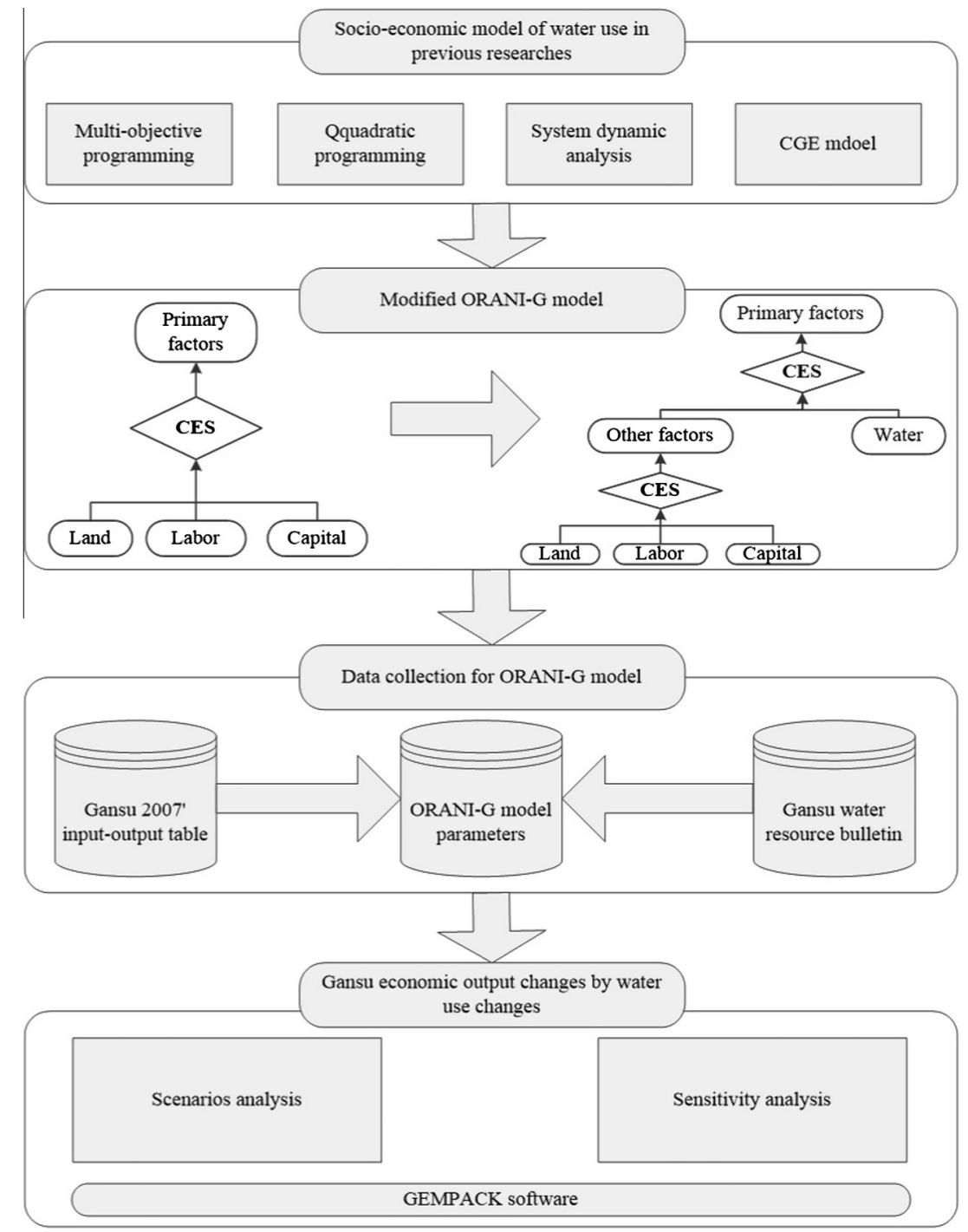

Fig. 3. Technical roadmap.

function. Land as the primary production factor is the first element to be nested, and sequentially labor and capital are embedded as well. The relevant parameters and variables are listed in the Appendix A.

$L N D_{i}=\operatorname{slnd}_{i} \cdot\left[\frac{\mathrm{POPRM}_{i}}{\mathrm{PLND}_{i}}\right]^{\sigma o p r m_{i}}$

$L A B_{i}=\operatorname{slab}_{i} \cdot\left[\frac{\text { POPRM }_{i}}{P L A B_{i}}\right]^{\sigma o p r m_{i}}$

$C A P_{i}=\operatorname{scap}_{i} \cdot\left[\frac{\text { POPRM }_{i}}{\text { PCAP }_{i}}\right]^{\sigma o p r m_{i}}$

$\operatorname{POPRM}_{i}=\left[\operatorname{slnd}_{i} \cdot \operatorname{PLND}_{i}^{1-\sigma o p r m_{i}}+\operatorname{slab}_{i} \cdot \operatorname{PLAB}_{i}^{1-\sigma o p r m_{i}}+\operatorname{scap}_{i} \cdot \text { PCAP }^{1-\sigma o p r m_{i}}\right]^{\frac{1}{1-\sigma o p r m}}$
$W T R_{i}=\operatorname{swtr}_{i} \cdot\left[\frac{\text { PPRIM }_{i}}{\text { PWTR }_{i}}\right]^{\sigma \text { prim }_{i}}$

$\mathrm{OPRM}_{i}=\operatorname{soprm}_{i} \cdot\left[\frac{\text { PPRIM }_{i}}{\text { POPRM }_{i}}\right]^{\text {бprim }} i$

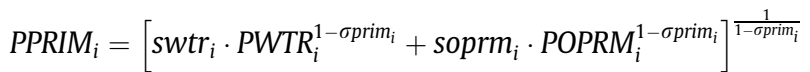

where $L N D_{i}$ is land input in the $i$ th commodity, $L A B_{i}$ is labor input in the $i$ th commodity, $C A P_{i}$ is capital input in the $i$ th commodity, $W T R_{i}$ is water input in the $i$ th commodity, $P W T R_{i}$ is water price, $P L N D_{i}$ is land price, $P L A B_{i}$ is labor price, $P C A P_{i}$ is capital price, $L A B O_{o, i}$ is $j$ type of labor input in the $i$ th commodity, $P L A B O_{o, i}$ is $j$ type of labor price in the $i$ th commodity. $\operatorname{sind}_{i}$ is the share of land input in the $i$ th commodity, $s l a b_{i}$ is the share of labor input in the ith commodity, $s c a p_{i}$ is 


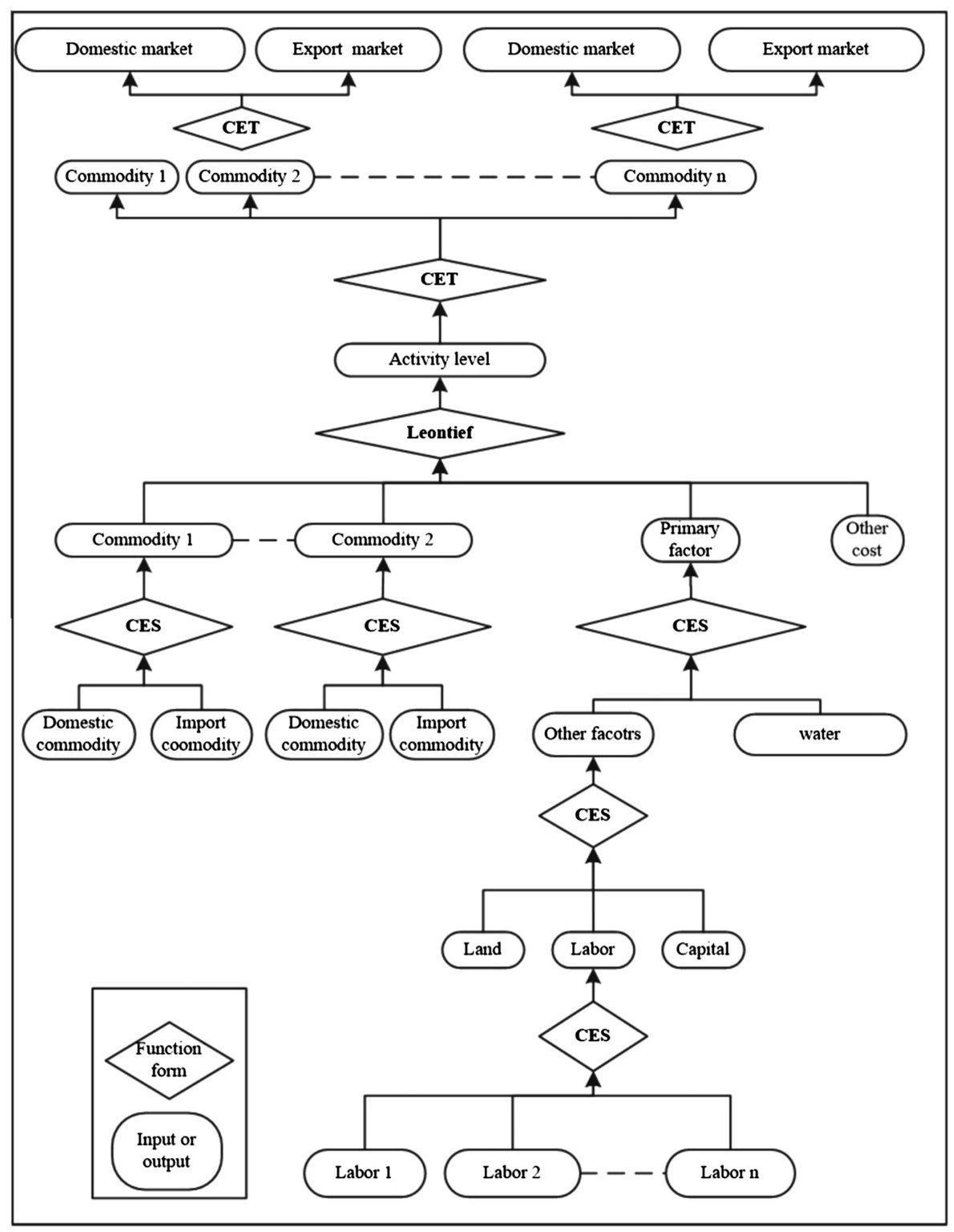

Fig. 4. A nested CES production function in the ORANI-G model. Note: CES (constant elasticity of substitution), CET (constant elasticity of transformation).

the share of capital input in the ith commodity, $\operatorname{soprm}_{i}$ is the share of intermediate input, oprim $_{i}$ is CES of land-labor-capital, $\sigma o p r o m_{i}$ is CES of water-CES (water-land-capital).

\subsubsection{Scenarios}

Simulation with multiple scenarios was carried out to analyze the impacts of water supply change on GDP and calculate the water productivity, and we set four scenarios that changing rate of water supply in all sectors, agricultural sector, industrial sector and urban construction, under which the change rate of water supply was set to be $-10 \%,-5 \%,-4 \%,-3 \%,-2 \%,-1 \%, 1 \%, 2 \%, 3 \%, 4 \%$, $5 \%$ and $10 \%$, respectively. The scenario without change in the water supply was used as the baseline scenario, and the results under other scenarios were compared with the result under the baseline scenario. In order to analyze the influence of water supply decrease on the economic development in Gansu Province, this study simulated the change rate of the output of various goods when the water supply decreases by $1 \%$, according to which the response of the output of different sectors to the water supply change was analyzed.

\section{Results}

\subsection{Empirical analysis}

The water was in introduced as a production factor into the ORANI-G model, and economic value of the water resource was calculated with the methodology mentioned above, the relationship between water supply and GDP was shown in Fig. 5. There is a linear positive correlation between the changes of GDP and water input changes. Based on the definition of the water productivity, the water productivity for total production is $0.47 \mathrm{USD} / \mathrm{m}^{3}$. Figs. $6-8$ shows the water productivity for agricultural production changes, industrial production changes, and commercial production changes, which is $0.16,2.23,4.21 \mathrm{USD} / \mathrm{m}^{3}$, respectively. This show the water inputs to GDP are underestimated by the market price, and the current water price fails to reflect the real economic 


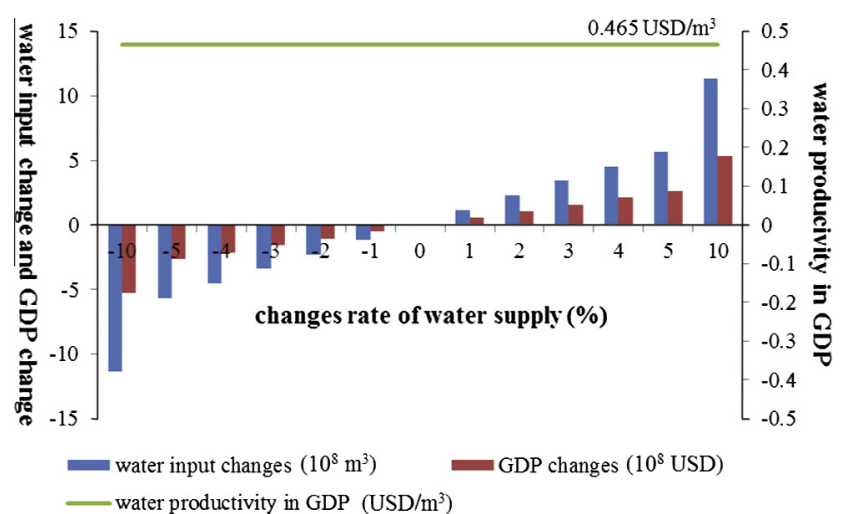

Fig. 5. Water productivity in Gansu.

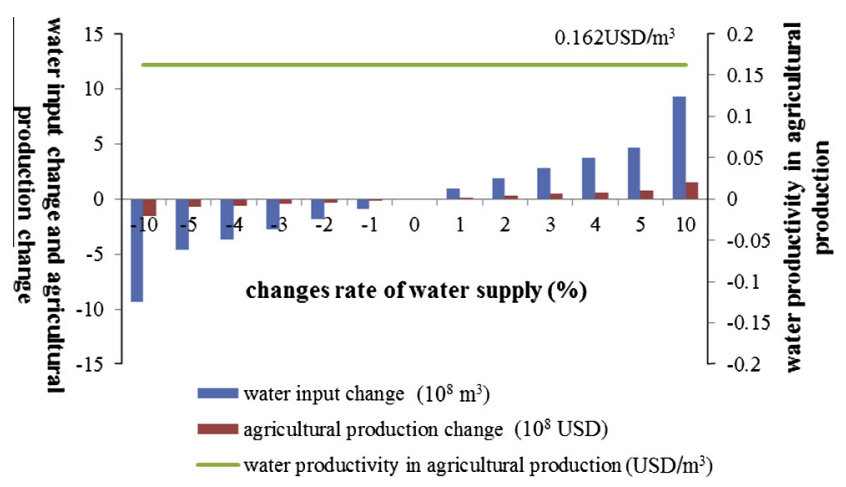

Fig. 6. Water productivity of agriculture industry in Gansu.

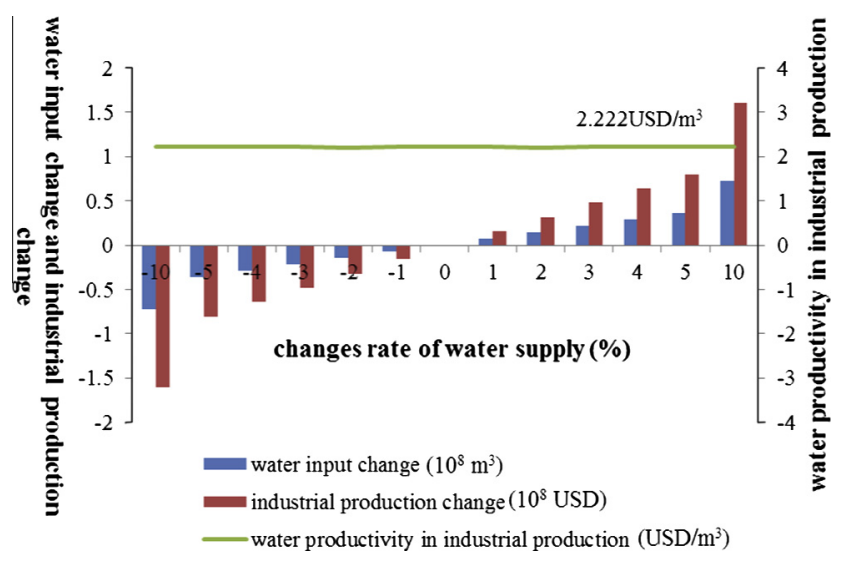

Fig. 7. Water productivity of industrial industry in Gansu.

value of water resources. In particular, since Gansu Province is located in the arid and semi-arid region, the underestimated water price indicates that the water scarcity in the study area is much severer than the description with the current market price. In other words, water allocation in Gansu Province is deviated from the optimum level at current water price.

The water productivity for agricultural production is 0.16 USD/ $\mathrm{m}^{3}$, which is close to $0.11 \mathrm{USD} / \mathrm{m}^{3}$ estimated by Wang (Wang et al., 2008) in the research of impact of agricultural water use on GDP in Zhangye City. Moreover, the efficiency of water use for agriculture is much lower than that for industrial and urban construction. In the investigation in the study area, we also found

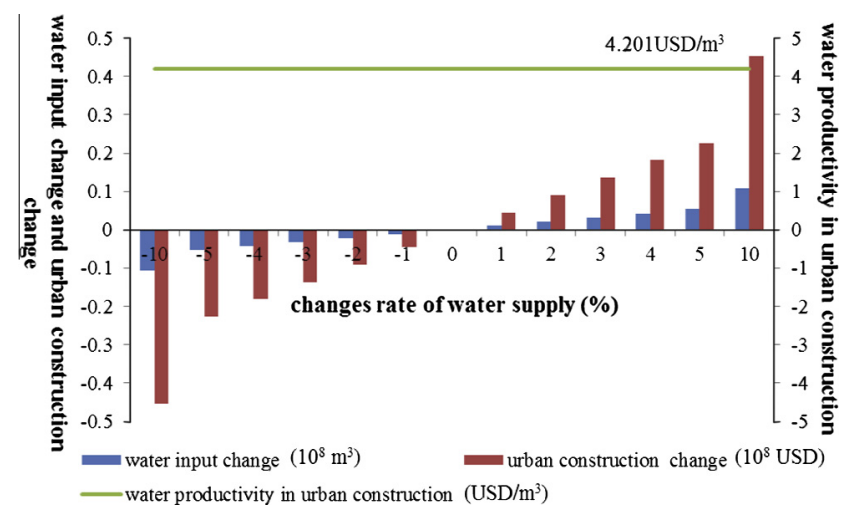

Fig. 8. Water productivity of urban construction in Gansu.

that the geographical and climatic characteristics in Gansu Province have great impacts on the evaporation and irrigation efficiency (Liang and Zhongxin, 2013), and therefore it is necessary to give priority to how to improve agricultural irrigation efficiency in integrated water resources management. Furthermore, structural reformation of economy in Gansu Province will also promote the decrease of water use of the agricultural industry and increase of the water use of the secondary and tertiary industry in order to eventually improve the efficiency of water use in Gansu Province.

Economic production is directly or indirectly driven by factor inputs of capital, labor, land and water in the CGE model, and therefore changes of economic production will be captured by our model when the water supply changes. In Fig. 9, when water as an almost irreplaceable natural capital input factor decreases by $1 \%$, the economic production will decrease under scenarios with the CES of water to other factors at 0.05 . Economic production of agriculture industry will decrease most obviously, with a decrease rate of about $0.381 \%$, while economic production of education will decrease by only $0.019 \%$. Since the economic production in the agriculture industry is more susceptible to the water input change than that of other sectors, improvement of the water use efficiency can bring more benefit to the agricultural production and mitigate the water scarcity in Gansu Province. By comparison, the economic production of the tertiary industry is less susceptible to the water input change than that of other sectors, and the water productivity in the tertiary industry is higher than that of other sectors. This indicates transformation of the economic structure in Gansu Province can promote the improvement of the water productivity. If water for agricultural production is shifted to other sectors, a large amount of water will be saved, and more economic production in the secondary and tertiary industries will be generated.

\subsection{Sensitivity analysis}

For sensitivity analysis, we designed scenarios with different CES of water to other factors, which is $0.01,0.05,0.1$, and 0.5 , respectively. When the water input decreases by $1 \%$, GDP will have different values under these four scenarios, and according to the simulation results, we can know how much changes of economic production will be caused by the water input change. Table 2 shows changes of GDP caused by water input change under different scenarios with different CES of water to other factors. We find the marginal change of GDP caused by water input change decreased from 1.15 to $0.12 \mathrm{USD} / \mathrm{m}^{3}$ when the CES increases, indicating the lower CES will lead to a higher sensitivity of GDP to the 


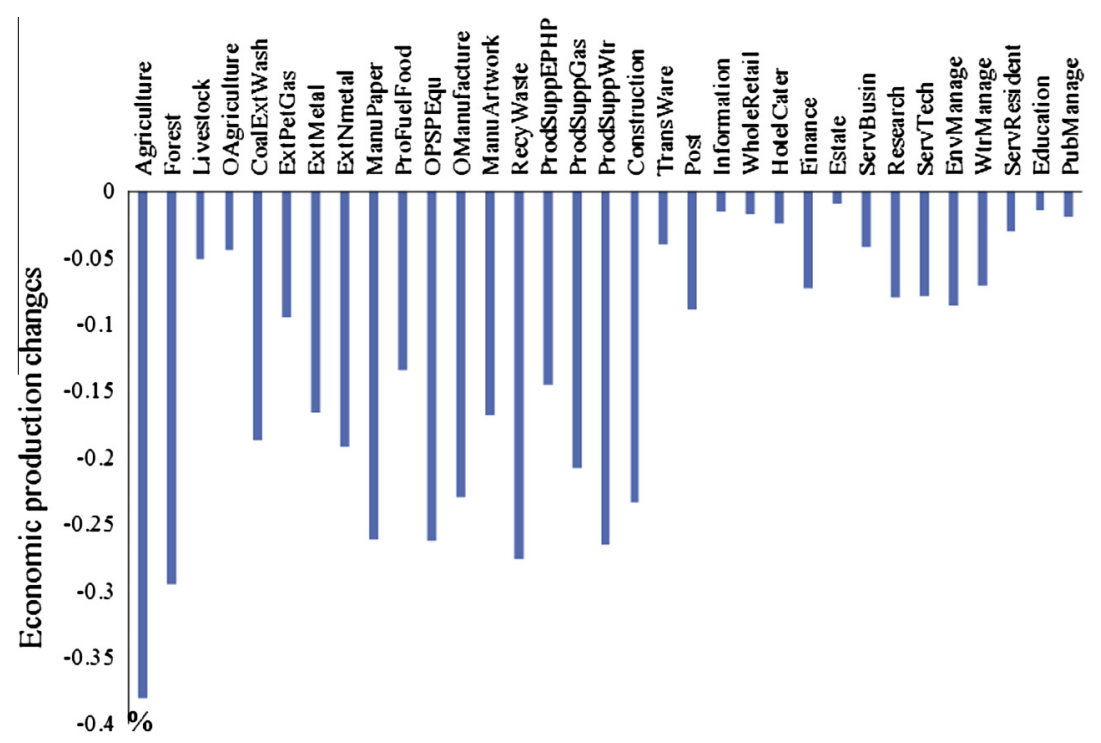

Fig. 9. Sectoral economic production changes by water input decrease $1 \%$ under CES of water to other factors at 0.05 in Gansu.

Table 2

Water productivity under different CES of water to other factors.

\begin{tabular}{lllllll}
\hline $\begin{array}{l}\text { CES } \\
\text { value }\end{array}$ & $\begin{array}{l}\text { GDP } \\
\text { changes } \\
\text { rate (\%) }\end{array}$ & $\begin{array}{l}\text { Water } \\
\text { supply } \\
10^{8} \mathrm{~m}^{3}\end{array}$ & $\begin{array}{l}\text { Water } \\
\text { supply } \\
\text { changes } \\
\text { in } 10^{8} \mathrm{~m}^{3}\end{array}$ & $\begin{array}{l}\text { GDP } \\
10^{8}\end{array}$ & $\begin{array}{l}\text { GDP } \\
\text { changes } \\
10^{8} \text { USD }\end{array}$ & $\begin{array}{l}\text { Water } \\
\text { productivity } \\
\text { USD } / \mathrm{m}^{3}\end{array}$ \\
\hline 0.01 & -0.31 & 112.61 & -1.14 & 419.96 & -1.31 & 1.15 \\
0.05 & -0.13 & 112.61 & -1.14 & 420.73 & -0.53 & 0.47 \\
0.10 & -0.08 & 112.61 & -1.14 & 420.93 & -0.33 & 0.29 \\
0.50 & -0.03 & 112.61 & -1.14 & 421.13 & -0.13 & 0.12 \\
\hline
\end{tabular}

water input change. GDP will change more dramatically when water supply changes a little if the water resource is close to the irreplaceable resource.

Since Gansu Province is located in the arid and semi-arid region, change of the water resource may have great influence on the economic development, and improvement of water productivity is vitally important to the local sustainable development. With the rapid technical progress of water recycling, the increased CES may mitigate the dependency of economic development on water inputs in the future, and therefore it is necessary to study how change of CES will influence the economic development. To study how the impacts of sensitivity of CES on GDP, graphical analysis was carried out on the changes of CES and changes of GDP in different sectors (Fig. 10). Although the sensitivity of CES to production changes is relatively high, the results show that the CES change has relatively small influence on the structural research findings. Compared to the impacts of direct water supply change on the production changes, the impacts of CES changes on the production changes are relatively small in each sector (Fig. 10).

\section{Discussion}

The water price is controlled by the local government in Gansu Province. It is usually difficult to implement uniform regulation of water resources management, but this issue is one of the factors that influence the research findings in our model. Since local government has access to free quota of water from the conservation area or other unofficial trade, the actual

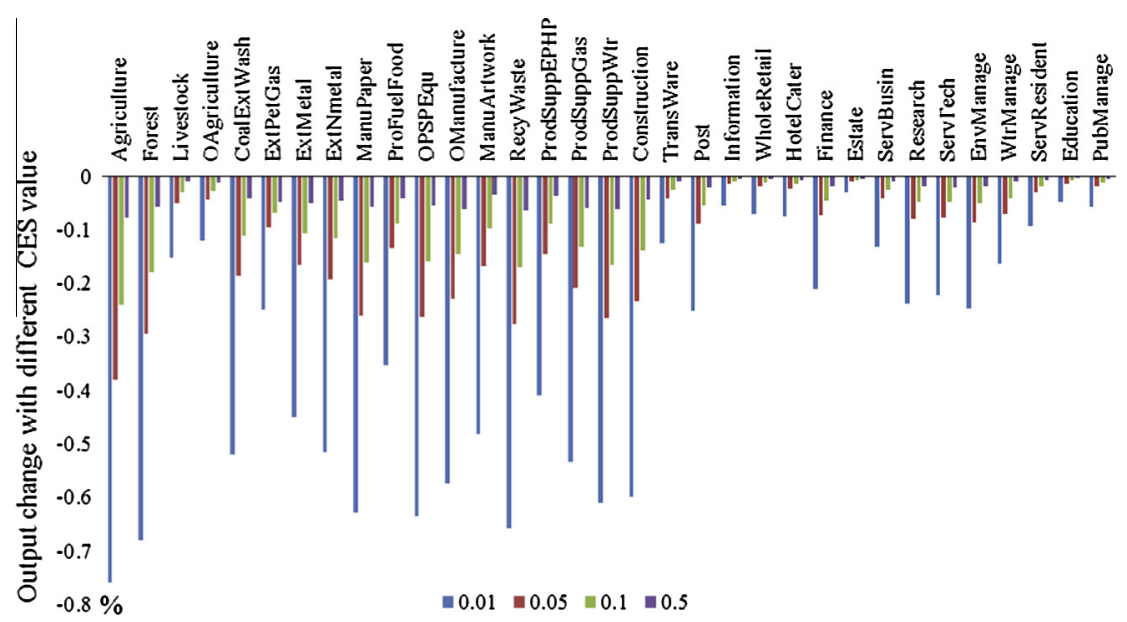

Fig. 10. Sectoral output percent change by water input decrease $1 \%$ under CES of water to other factors at 0.05 in Gansu. 
water use amount might be different from that in the published data reports, and consequently the actual total amount of water use and supply might be a bit different from the data used in our model. But most of the unaccounted water use comes from agricultural irrigation, which is at a low price and even for free, and as a result the unaccounted water use has very limited influence our finding even tough agricultural irrigation accounts for the largest proportion of water consumption. Furthermore, CES of water to other factors can indirectly influence the production in each sector. Although it has relatively smaller impacts compared to the water supply changes, it still represents the technical coefficient of water to production in each sector. As a result CES of water to other factors can directly influence the water productivity in each sector, and improvement of the agricultural water productivity is of vital importance to enhancing the overall water use efficiency in Gansu Province. Again, since agricultural irrigation consumes the largest proportion of water resources, reformation of the industrial structure and development of water-saving production can effectively mitigate the water shortage in Gansu Province.

\section{Conclusion}

We improved the ORANI-G model by introducing the water resource into the CES production function, and a dataset for the modified ORANI-G model was established on the basis of the Gansu Input-Output Table 2007 and Gansu Water Resource Bulletin 2007. Based on the definition of water productivity, we analyzed water productivity changes caused by change of the water input, and sensitivity analysis showed that our model is reliable and robust.

The results firstly show that the current water productivity is underestimated. Secondly, agricultural water use accounts for the largest part of water consumption in Gansu Province, and therefore enhancing agricultural water productivity can greatly mitigate the water shortage. Thirdly, the water productivity of the agriculture industry is lower than that of the secondary and tertiary industries. This indicates that reformation of the industrial structure and development of water-saving industries can also mitigate the water shortage. Fourthly, the results of sensitivity analysis show that CES changes have relatively small impacts on production in each sector, but a higher CES of water to other production factors can still contribute to the sustainable development.

\section{Conflicts of Interest}

The authors declare no conflict of interest.

\section{Author contributions}

All authors read and approved the final manuscript.

\section{Acknowledgments}

This research was financially supported by the major research plan of the National Natural Science Foundation of China (Grant No. 91325302), the National Natural Science Funds of China for Distinguished Young Scholar (Grant No. 71225005). The authors would like to thank Yingzhi Lin and Fan Zhang from School of Mathematics and Physics, China University of Geosciences (Wuhan).

\section{Appendix A}

\begin{tabular}{ll}
\hline Variable name & Implication \\
\hline$L N D_{i}$ & Land input \\
$L A B_{i}$ & Labor input \\
$C A P_{i}$ & Capital input \\
$W T R_{i}$ & Water input \\
$P W T R_{i}$ & Water price \\
$P L N D_{i}$ & Land price \\
$P L A B_{i}$ & Labor price \\
$P C A P_{i}$ & Capital price \\
$L A B O_{o, i}$ & $j$ type of labor input \\
$P L A B O_{o, i}$ & $j$ type of labor price \\
Parameter name & Implication \\
\hline slnd $_{i}$ & share of land input \\
slab $_{i}$ & share of labor input \\
Scap $_{i}$ & share of capital input \\
soprm $_{i}$ & share of intermediate input \\
$\sigma \operatorname{oprim}_{i}$ & CES of land-labor-capital \\
$\sigma o p r o m_{i}$ & CES of water-CES (land-labor-capital) \\
\hline
\end{tabular}

\section{References}

Baker, J.E., 2011. The impact of including water constraints on food production within a CGE framework. Doctoral dissertation, Massachusetts Institute of Technology.

Berrittella, M., Hoekstra, A.Y., Rehdanz, K., Roson, R., Tol, R.S., 2007. The economic impact of restricted water supply: a computable general equilibrium analysis. Water Res. 41 (8), 1799-1813.

Brown, A., Matlock, M.D., 2011. A review of water scarcity indices and methodologies. Sustain. Consortium, White Paper 106, 19.

Calzadilla, A., Rehdanz, K., Tol, R.S., 2010. The economic impact of more sustainable water use in agriculture: a computable general equilibrium analysis. J. Hydrol. 384 (3), 292-305.

Calzadilla, A., Rehdanz, K., Tol, R.S., 2011a. Trade liberalization and climate change: a computable general equilibrium analysis of the impacts on global agriculture. Water 3 (2), 526-550.

Calzadilla, A., Rehdanz, K., Tol, R.S., 2011b. Water scarcity and the impact of improved irrigation management: a computable general equilibrium analysis. Agric. Econ. 42 (3), 305-323.

Calzadilla, A., Rehdanz, K., Tol, R.S., 2011. The GTAP-W model: accounting for water use in agriculture (No. 1745). Kiel Working Papers.

Calzadilla, A., Zhu, T., Rehdanz, K., Tol, R.S., Ringler, C., 2014. Climate change and agriculture: impacts and adaptation options in South Africa. Water Resour Econ. 5, 24-48.

Chen, Y., Zhang, D., Sun, Y., Liu, X., Wang, N., Savenije, H.H., 2005. Water demand management: a case study of the Heihe River Basin in China. Phys. Chem. Earth, Parts A/B/C 30 (6), 408-419.

Chen, Z., Wei, S., 2014. Application of system dynamics to water security research. Water Resour. Manage. 28 (2), 287-300.

Cheong, T., Ko, I., Labadie, J., 2010. Development of multi-objective reservoir operation rules for integrated water resources management. J. Hydroinformatics 12 (2), 185-200.

Deng, X., Zhang, F., Wang, Z., Li, X., Zhang, T., 2014. An extended input output table compiled for analyzing water demand and consumption at county level in China. Sustainability 6 (6), 3301-3320.

Diao, X., Dinar, A., Roe, T., Tsur, Y., 2008. A general equilibrium analysis of conjunctive ground and surface water use with an application to Morocco. Agric. Econ. 38 (2), 117-135.

Diao, X., Roe, T., Doukkali, R., 2005. Economy-wide gains from decentralized water allocation in a spatially heterogenous agricultural economy. Environ. Dev. Econ. 10 (03), 249-269.

Farmani, R., Savic, D.A., Walters, G.A., 2005. Evolutionary multi-objective optimization in water distribution network design. Eng. Optimiz. 37 (2), 167 183.

Gómez, C.M., Tirado, D., Rey-Maquieira, J., 2004. Water exchanges versus water works: insights from a computable general equilibrium model for the Balearic Islands. Water Resour. Res, 40 (10).

Goulter, I., 1995. Multiobjective water resources investment planning under budgetary uncertainty and fuzzy environment. Eur. J. Oper. Res. 82 (3), 556591. 
Huang, G., 1996. IPWM: an interval parameter water quality management model. Eng. Optimiz.+ A35 26 (2), 79-103.

Huang, G., Loucks, D.P., 2000. An inexact two-stage stochastic programming mode for water resources management under uncertainty. Civ. Eng. Syst. 17 (2), 95 118.

Huang, G., Li, Y., Xiao, H., Qin, X., 2007. An inexact two-stage quadratic program for water resources planning. J. Environ. Inform. 10 (2), 99-105.

Kummu, M., Ward, P.J., de Moel, H., Varis, O., 2010. Is physical water scarcity a new phenomenon? Global assessment of water shortage over the last two millennia. Environ. Res. Lett. 5 (3), 034006.

Liang, S., Chen, Z., 2013. Estimation of regional evapotranspiration based on Penman-Monteith equation and soil moisture index. Trans. Chin. Soc. Agric. Eng. 2013 (10)

Liu, Y., Huang, J., Wang, J., Scott, R., 2008. Determinants of Agricultural Water Saving Technology Adoption: An Empirical Study of Ten Provinces of China. Ecological Economy 4, 462-472.

Liu, Y., Cai, Y., Huang, G., Dong, C., 2012a. Interval-parameter chance-constrained fuzzy multi-objective programming for water pollution control with sustainable wetland management. Procedia Environ. Sci. 13, 2316-2335 (Complete).

Liu, J., 2013. The Application and Extensions of Coordinated Water and SocioEconomic Development Model (CWSE-E). China Institute of Water Resources \& Hydropower Research (IWHR) (in Chinese).

Liu, J., Ni, H.Z., Wang, D.X., Huang, X.L., 2012b. Analysis of economic effects of Tianjin water resources based on CGE model. J. China Inst. Water Resour. Hydropower Res. 10, 192-198 (in Chinese).

Martin-Carrasco, F., Garrote, L., Iglesias, A., Mediero, L., 2013. Diagnosing causes of water scarcity in complex water resources systems and identifying risk management actions. Water Resour. Manage. 27 (6), 1693-1705.

Miller, R.E., Blair, P.D., 2009. Input-Output Analysis: Foundations and Extensions. Cambridge University Press.

Playán, E., Mateos, L., 2006. Modernization and optimization of irrigation systems to increase water productivity. Agric. Water Manage. 80 (1), 100-116.

Qi, C., Chang, N.B., 2011. System dynamics modeling for municipal water demand estimation in an urban region under uncertain economic impacts. J. Environ. Manage. 92 (6), 1628-1641.
Schreider, S., July 2009. Water price dynamics, water derivatives and general equilibrium modelling. In: Anderssen, R.S., Braddock, R.D., Newham, L.T.H (Eds.), 18th World IMACS Congress and MODSIM09 International Congrev. $v$ on Modelling and Simulation (July 2009), pp. 3640-3646.

Seung, C.K., Englin, J.E., Harris, T.R., July 1997. Application of computable general equilibrium model to derive impacts of surface water reallocation policy. In: Western Agricultural Economics Association 1997 Annual Meeting July, pp. 1316.

Shi, M., Tao, W., Zhao, X., 2010. A GIS-based bio-economic model applied in water resource management in Shiyang River Basin, Gansu Province, China. In: Sustainability in Food and Water. Springer, Netherlands, pp. 61-71.

Stave, K.A., 2003. A system dynamics model to facilitate public understanding of water management options in Las Vegas, Nevada. J. Environ. Manage. 67 (4), 303-313.

Sušnik, J., Vamvakeridou-Lyroudia, L.S., Savić, D.A., Kapelan, Z., 2012. Integrated system dynamics modelling for water scarcity assessment: case study of the Kairouan region. Sci. Total Environ. 440, 290-306.

Wang, Y., Xiao, H.L., Ren, J., Lu, M.F., 2008. Study on water resources utilization in Zhangye City based on CGE model. Arid Zone Res. 1, 28-34 (in Chinese).

Winz, I., Brierley, G., Trowsdale, S., 2009. The use of system dynamics simulation in water resources management. Water Resour. Manage. 23 (7), 1301-1323.

Wittwer, G., 2006. Modelling future urban and rural water requirements in a CGE framework. In: 2006 Conference (50th), February 8-10, 2006, Sydney, Australia (No. 139928). Australian Agricultural and Resource Economics Society.

Wittwer, G. (Ed.), 2012. Economic Modeling of Water: The Australian CGE Experience, vol. 3. Springer.

Wu, F., Zhan, J., Wang, Z., Zhang, Q., 2014. Streamflow variation due to glacier melting and climate change in upstream Heihe River Basin, Northwest China. Phys. Chem. Earth, Parts A/B/C.

Xevi, E., Khan, S., 2005. A multi-objective optimisation approach to water management. J. Environ. Manage. 77 (4), 269-277.

Yapo, P.O., Gupta, H.V., Sorooshian, S., 1998. Multi-objective global optimization for hydrologic models. J. Hydrol. 204 (1), 83-97.

Zhang, Q., Liu, B., Zhang, W., Jin, G., Li, Z., 2014. Assessing the regional spatiotemporal pattern of water stress: a case study in Zhangye City of China. Phys. Chem. Earth, Parts A/B/C. 